\title{
Streptococcal Bacteraemia in Children Following Dental Extractions
}

\author{
R. H. ELLIOTT and J. M. DUNBAR \\ From Royal Belfast Hospital for Sick Children, and the Department of Microbiology, Queen's University of Belfast
}

Since the work of Okell and Elliott (1935) and of Burket and Burn (1937), it has been established that a bacteraemia occurs in many cases after dental manipulation, particularly where periodontal disease is present. This bacteraemia is transient, lasting about 10 minutes according to Northrop and Crowley (1943) and up to 30 minutes according to Shafer, Hine, and Levy (1963). It is usually considered of little significance except in patients with rheumatic or congenital heart disease, where the danger of subacute bacterial endocarditis is very real.

None of the studies undertaken previously has had special reference to children. It was thought that in view of the rarity of gross periodontal disease in children, and the smaller degree of manipulation necessary for the extraction of deciduous and young permanent teeth, it would be of value to investigate a series of children with regard to the incidence of bacteraemia resulting from dental extractions.

This study was also concerned with the effect of pre-extraction antibiotic therapy on the incidence of this bacteraemia. In the latter part of the study and following the work of Stirland and Shotts (1967), antibiotic sensitivity tests were undertaken on $\alpha$-haemolytic streptococci found in the saliva of a series of children with and without cardiac lesions.

\section{Material and Methods}

Three groups of children undergoing dental extractions and between the ages of 2 and 13 years were studied.

Group I consisted of 100 out-patients who had no cardiac lesions and who were not receiving antibiotic therapy. These children served as a control group.

Group II consisted of 100 children with known cardiac lesions who required dental extraction under antibiotic cover. Of these, 11 had lesions of rheumatic origin, and 9 of these were receiving long-term prophylactic penicillin. 53 had proven congenital defects. The remainder were children who were given antibiotic

Received February 12, 1968. cover before operation because of murmurs that were still under investigation. The drug of choice was penicillin except where the patient was (a) receiving prophylactic penicillin for rheumatic heart disease or had very recently received a course of penicillin, (b) allergic to penicillin, or in the latter part of the study, (c) found to be harbouring penicillin-resistant $a-$ haemolytic streptococci in the mouth. In these circumstances where penicillin was contraindicated, erythromycin, ampicillin, or tetracycline was used.

I Group III consisted of 17 children receiving antibiotic therapy for acute inflammatory oral or dental lesions. They had no cardiac lesions.

The mean age of each group was, respectively, $6 \cdot 6$, $7 \cdot 5$, and $5 \cdot 4$ years.

Blood culture. Blood was obtained 2 to 5 minutes after beginning the manipulation of the tooth or teeth. It was not considered justifiable to obtain intravenous blood samples of the order used in some of the adult studies (Hampp, 1959: $45 \mathrm{ml}$. with $10 \mathrm{ml}$. pre-operatively; Francis et al., 1962: $20 \mathrm{ml}$.; Okell and Elliott, 1935: 10 ml. post-operatively). In this series a single sample of $5 \mathrm{ml}$. was thought to be the upper limit, and over $3 \mathrm{ml}$. was considered sufficient. No pre-operative samples were taken.

Blood withdrawn using sterile precautions was transferred to $50 \mathrm{ml}$. culture medium. The medium selected was brain heart infusion, with addition of $0.1 \%$ agar, $0.2 \%$ sodium citrate, and $0.1 \%$ white saponin, as recommended for isolation of a-haemolytic streptococci (Cruickshank, 1965). This was incubated at $37^{\circ} \mathrm{C}$. for 6 days. If the child was receiving penicillin, penicillinase (Burroughs Wellcome) was added in the proportion of $0.01 \mathrm{ml}$. to $100 \mathrm{ml}$. of blood culture medium. Subcultures were taken after 2, 4, and 6 days of incubation, and plated on both blood agar and heated blood agar. These were then incubated under aerobic and anaerobic conditions. Colonies of $a$-haemolytic streptococci showing typical bleaching or greening were further tested by biochemical reactions and for sensitivity to benzyl penicillin, cloxacillin, methicillin, ampicillin, tetracycline, chloramphenicol, streptomycin, and erythromycin using Evans Sentests and Oxoid Multodiscs.

Saliva culture. This series included many children not in the other groups, as this investigation was started later than our original study. 
Sensitivity tests on $a$-haemolytic streptococci isolated from saliva specimens were carried out either by direct or indirect testing. The direct sensitivity test method was that of Garrod and Waterworth (1962), using 10 units of penicillin.

The indirect method consisted of taking a swab specimen of saliva from the sublingual region and plating out on blood agar and heated blood agar to obtain discrete colonies. An additional medium consisting of blood agar (Oxoid No. 2) containing 1/1000 sodium acid selenite $\left(\mathrm{NaHSeO}_{3}\right)$ was also inoculated with the same specimens. Selected colonies were used as inoculum for sensitivity tests against the 8 antibiotics used.

\section{Results}

\section{Blood culture findings}

Group I: In this group of 100 children, $36 \%$ of the blood cultures yielded $\alpha$-haemolytic streptococci as shown in Table $I$.

In 79 of these children the extractions were of deciduous teeth only, and $32 \%$ of these yielded $\alpha$-haemolytic streptococci. In 10 children who had extraction of both deciduous and permanent teeth the figure was $40 \%$, and where permanent teeth only were extracted from 11 children the figure rose to $64 \%$.

Analysis by age showed a higher percentage of positive cultures in the 8-13-year group (52\%) when compared to the 2-7 year olds (31\%).

Of 11 cases of difficult extractions requiring more than average manipulation, $8(73 \%)$ had positive cultures. These were in the higher age-group.
TABLE I

Blood Culture Findings in Three Groups of Children

\begin{tabular}{c|c|c|c}
\hline Group & Total & $\begin{array}{c}\alpha \text {-Haemolytic } \\
\text { Streptococci } \\
\text { Isplations }\end{array}$ & $\begin{array}{c}\text { Total Blood } \\
\text { Cultures } \\
\text { Positive }\end{array}$ \\
\hline I $\left\{\begin{array}{l}\text { No cardiac lesion } \\
\text { No antibiotic cover }\end{array}\right.$ & 100 & 36 & 55 \\
II $\left\{\begin{array}{l}\text { Cardiac lesion } \\
\text { Antibiotic cover }\end{array}\right.$ & 100 & 11 & 19 \\
III $\left\{\begin{array}{l}\text { No cardiac lesion } \\
\text { Antibiotic therapy }\end{array}\right.$ & 17 & 6 & 9 \\
\hline
\end{tabular}

No organisms were recovered from 4 children who had sound permanent teeth extracted for orthodontic reasons.

Group II: In this group of 100 children $11 \%$ yielded $\alpha$-haemolytic streptococci. An analysis of the antibiotic cover used (Table II) showed that of the 22 patients who received oral penicillin before operation, $8(36 \cdot 3 \%)$ yielded organisms on culture, $4(18 \cdot 2 \%)$ being $\alpha$-haemolytic streptococci. Of the 51 who were given benzyl penicillin $\frac{1}{2}$ mega intramuscularly $\frac{1}{2}-1$ hour before operation, $4(7 \cdot 8 \%)$ had positive cultures, $2(3.9 \%)$ being $\alpha$-haemolytic streptococci.

Table II section 4 shows the results when 10 children on long-term prophylactic penicillin were given alternative medication. 9 of these children had lesions of rheumatic origin; tetracycline hydrochloride gave 2 positive cultures out of 3,

TABLE II

Analysis of Antibiotic Cover and Bacteriological Findings in 100 Children (Group II) with Cardiac Lesions

\begin{tabular}{|c|c|c|c|c|c|c|c|}
\hline & & & & $\begin{array}{l}\text { No. of } \\
\text { Children }\end{array}$ & $\begin{array}{l}\alpha-\text { Haemolytic } \\
\text { Streptococcus }\end{array}$ & $\begin{array}{l}\text { Staphylococcus } \\
\text { albus }\end{array}$ & $\begin{array}{c}\% \text { Isolation } \\
\alpha \text {-Haemolytic } \\
\text { Streptococcus }\end{array}$ \\
\hline 1: Benzyl penicillin $\frac{1}{2}$ mega $\frac{1}{2}-1$ hour & pre-operatively & $y$. & .. & 51 & 2 & 2 & $3 \cdot 9$ \\
\hline 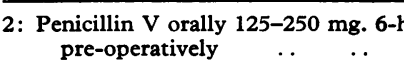 & $\begin{array}{c}\text { ourly } 3 \text { doses } \\
\ldots \quad \ldots\end{array}$ & .. & .. & 22 & 4 & 4 & $18 \cdot 2$ \\
\hline $\begin{array}{l}\text { 3: Procaine penicillin } \\
\begin{aligned} \text { (i) } 300,000 \text { units 4-5 hours pre } \\
\text { (ii) }+ \text { penicillin V orally, } 250 \mathrm{~m} \\
\text { pre-operatively } \\
\text { (iii) }+ \text { benzyl penicillin } \frac{1}{2} \text { mega } \\
\text { pre-operatively } \quad .\end{aligned}\end{array}$ & $\begin{array}{l}\text {-operatively } \\
\text { g. 6-hourly } 2 \mathrm{~d} \\
\text {.. } \quad \ldots \\
\text { iven } 3 \text { days } \\
\ldots \quad \text {. } \quad .\end{array}$ & $\begin{array}{l} \\
\ldots \\
\text { doses } \\
\ldots\end{array}$ & $\cdots$ & $\begin{array}{l}6 \\
5 \\
1\end{array}$ & $\begin{array}{l}0 \\
2 \\
1\end{array}$ & $\begin{array}{l}0 \\
0 \\
0\end{array}$ & 25 \\
\hline 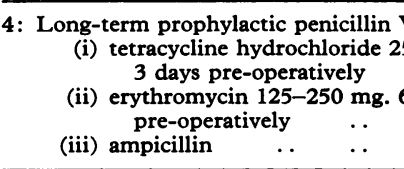 & 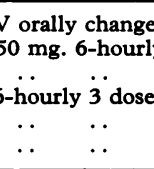 & $\begin{array}{l}\text { ed to: } \\
\text { ly for } \\
\ldots \\
\text { es } \\
\cdots\end{array}$ & $\begin{array}{l}\cdots \\
\cdots \\
\cdots\end{array}$ & $\begin{array}{l}3 \\
5 \\
2\end{array}$ & $\begin{array}{l}2 \\
0 \\
0\end{array}$ & $\begin{array}{l}0 \\
0 \\
0\end{array}$ & 20 \\
\hline 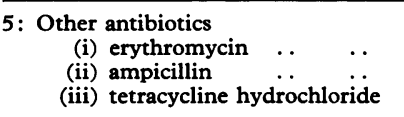 & $\begin{array}{ll}\cdots & \cdots \\
\cdots & \cdots \\
\cdots & \cdots\end{array}$ & $\begin{array}{l}. . \\
\cdots \\
\cdots\end{array}$ & $\begin{array}{l}\cdots \\
\cdots \\
\cdots\end{array}$ & $\begin{array}{l}2 \\
2 \\
1\end{array}$ & $\begin{array}{l}0 \\
0 \\
0\end{array}$ & $\begin{array}{l}1 \\
0 \\
0\end{array}$ & 0 \\
\hline
\end{tabular}


while 5 children receiving erythromycin and 2 receiving ampicillin gave no positive cultures.

Group III: In this group of 17 children, $6(35 \%)$ yielded $\alpha$-haemolytic streptococci. Of the 17 children, 11 had received oral penicillin for varying times from 5 days to 12 hours before operation, and of these, 4 had $\alpha$-haemolytic streptococci on culture. Of 5 children given benzyl penicillin, one who had had a single intramuscular injection 17 hours before operation yielded $\alpha$-haemolytic streptococci. The blood from one child who had been on sulphonamides for 5 days yielded $\alpha$-haemolytic streptococci.

Antibiotic sensitivity results on 50 isolates of streptococci from blood samples. It was found that all strains were sensitive to ampicillin and chloramphenicol and only one was resistant to benzyl penicillin. Of the 33 strains obtained from children not receiving antibiotics, only 3 showed resistance; 2 of these were resistant to cloxacillin only, and one resistant to both cloxacillin and streptomycin. Of the 11 strains isolated from children with cardiac damage and receiving antibiotics, only 3 were fully sensitive to the antibiotics tested. Of the remainder, 4 were resistant to cloxacillin, 1 to both cloxacillin and methicillin, 1 to cloxacillin, methicillin, and streptomycin, 1 to cloxacillin and tetracycline, and 1 to streptomycin only. Of the 6 strains of $\alpha$-haemolytic streptococci isolated from children receiving various regimens of penicillin for oral lesions, 4 were found to be insensitive to cloxacillin.

\section{Saliva culture}

Direct sensitivity results. A total of 56 saliva specimens was examined using this method, and all but one yielded a growth of $\alpha$-haemolytic streptococci. Of these, 22 strains were obtained from children without cardiac defects and not receiving antibiotic cover. All of these streptococci were sensitive to benzyl penicillin. Of the 33 streptococcal strains from children with a recognized cardiac lesion, 27 strains were sensitive and 6 were resistant to benzyl penicillin ( $18 \%$ ).

Indirect sensitivity results. It was found that selenite blood agar medium gave almost pure growths of mouth streptococci. The colonies of $\alpha$-haemolytic streptococci on this medium were deep rose red to ruby red in colour, opaque, and reaching $0.5 \mathrm{~mm}$. in diameter after 18 hours' incubation. On heated blood agar the $\alpha$-haemolytic streptococci tended to be overgrown by other organisms present in the specimens of saliva. Of the 27 saliva specimens plated on selenite medium, 26 gave a growth of $\alpha$-haemolytic streptococci, and of 16 specimens obtained from children with a cardiac lesion, 3 strains were found to be resistant to benzyl penicillin (19\%). Two of these children, though carrying a penicillin resistant strain in the mouth, failed to give any growth on blood culture. Only 1 of the 10 specimens from children with no cardiac lesion and not on antibiotic therapy yielded an $\alpha$-haemolytic streptococcus resistant to benzyl penicillin.

As these saliva cultures were undertaken when the original study was well advanced, only one of the children in Group II on long-term prophylactic penicillin was tested. In this case the $\alpha$-haemolytic streptococci were penicillin resistant.

\section{Discussion}

The isolation rate of $\alpha$-haemolytic streptococci in the control group (Group I) is close to that found by Okell and Elliott (1935) for extraction of teeth in adults with no noticeable periodontal disease, and similar to that described by Rhoads, Schram, and Adair (1950) after removal of teeth. Allowing for difference in methods, it seems that the special factors operating in children did not diminish the possibility of acquiring a temporary $\alpha$-haemolytic streptococcal bacteraemia.

Where penicillin was used as a cover, the best results were obtained using benzyl penicillin intramuscularly $\frac{1}{2}-1$ hour before operation, where only 2 out of 51 blood cultures yielded $\alpha$-haemolytic streptococci within 5 minutes of dental extraction. Oral penicillin gave relatively poor results, with 4 children out of 22 yielding $\alpha$-haemolytic streptococci. The American Heart Association accepts the use of oral penicillin as a useful alternative cover (1965). Garrod and Waterworth (1962) have pointed out the inadvisability of starting penicillin treatment several days before the extraction of teeth. One child in Group II who had been given benzyl penicillin 3 days before extraction followed by procaine penicillin yielded $\alpha$-haemolytic streptococci on blood culture, as did one child in Group III who had been given benzyl penicillin for 4 days before extraction, followed by a course of oral penicillin.

The marked reduction using benzyl penicillin may have been in part due to a high blood level with carry-over of penicillin to the blood culture medium, but considering the various factors it was felt that 10 units penicillinase $/ \mathrm{ml}$. added to the blood culture medium would prevent this. It is also possible that this dose of benzyl penicillin might allow greater diffusion into the tissues and fluids of the mouth with resulting depression of oral streptococci.

The results from the remaining cases in this 
group who were given other antibiotics-ampicillin, tetracycline, erythromycin, cannot easily be compared with the above cases, either because of their small number or the lack of an inhibitor similar to penicillinase. Where penicillin was contraindicated, erythromycin or ampicillin was used in this study. However, Tozer, Boutflower, and Gillespie (1966) found cephaloridine to be the best drug in these circumstances. The oral administration of erythromycin and ampicillin is an advantage in children.

The children in Group III had been given antibiotic therapy for various reasons, mostly acute inflammatory conditions. Though the inflammatory lesions had healed in these children, the results show that the streptococcal bacteraemia may still occur.

Stirland and Shotts (1967) have stressed the advisability of pre-extraction sensitivity tests on oral organisms. In our series on both direct and indirect saliva sensitivity tests, approximately $18 \%$ of the children with, and $3 \%$ of those without cardiac lesions had penicillin-resistant organisms. This increased resistance in children with cardiac lesions may be a reflection of increased contact with the hospital environment and more frequent use of antibiotics both in and out of hospital, perhaps even for otherwise trivial illness.

However, in contrast to the frequent finding of resistant strains in the saliva, in our series of 100 children with cardiac lesions and receiving antibiotic cover, 11 yielded $\alpha$-haemolytic streptococci on blood culture, but only one strain $(9 \%$ ) was found to be resistant to benzyl penicillin. Approximately $40 \%$ of all $\alpha$-haemolytic streptococci isolated from blood showed some degree of resistance to cloxacillin, and it is suggested that cloxacillin may serve as a useful marker in the antibiogram.

\section{Conclusions}

This study indicates that intramuscular benzyl penicillin given $\frac{1}{2}-1$ hour before dental extraction gives the best protection to children with cardiac disease, and this is in agreement with the recommendation of the American Heart Association. These studies suggest that oral administration of penicillin $\mathrm{V}$ is less effective. This is the alternative recommendation of the American Heart Association, and is also the suggested treatment schedule for children under 14 years of the National Heart Foundation of Australia (1965). Guidance in the choice of antibiotic cover may be obtained from pre-extraction saliva sensitivity tests.

\section{Summary}

A post dental extraction $\alpha$-haemolytic strepto- coccal bacteraemia was found in 36 out of 100 children not receiving antibiotic therapy. In children known to have cardiac lesions and given various antibiotic regimens, viable $\alpha$-haemolytic streptococci were detected in the blood of 11 out of 100 children within 5 minutes of dental extraction. Children given benzyl penicillin intramuscularly $\frac{1}{2}-1$ hour before operation showed the lowest isolation rate in this study $(3.9 \%)$, while relatively poor results were obtained using oral penicillin $(18 \cdot 2 \%)$. Penicillin therapy adequate for infectious oral conditions may not be sufficient to reduce materially the incidence of post dental extraction bacteraemia. Streptococci isolated from the blood of children with known cardiac defects were frequently resistant to one or more antibiotics. Resistance to penicillin was more frequent in streptococci isolated from saliva of children with cardiac lesions than those without heart damage.

We are most grateful to the staff in the Royal Belfast Hospital for Sick Children, especially Dr. S. H. S. Love, Mr. J. C. McNeill, L.D.S., F.F.D., R.C.S.I., Miss H. Smyth, R.S.C.N., Mr. I. D. Saunders, B.D.S., and Mrs. R. Manning in the Dental Department for their help with the clinical side of this study: Drs. J. F. Pantridge and G. Patterson of the Cardiac Clinic for their co-operation; and Professor I. J. Carré for his most valuable criticism.

We also wish to thank Mr. J. Evans, F.I.M.L.T., of the Microbiology Department, Queen's University of Belfast, for his technical assistance.

\section{REFERENCES}

American Heart Association (1965). Prevention of bacterial endocarditis. Circulation, 31, 953.

Burket, L. W., and Burn, C. G. (1937). Bacteremias following dental extractions. F. Dent. Res., 16, 521 .

Cruickshank, R. (1965). Medical Microbiology, 11th ed., p. 801. Livingstone, Edinburgh.

Francis, L. E., De Vries, J. A., Soomsawasdi, P., and Platonow, M. (1962). Control of postextraction bacteraemias. F. Canad. dent. Ass., 28, 683.

Garrod, L. P., and Waterworth, P. M. (1962). The risks of dental extraction during penicillin treatment. Brit. Heart f., 24, 39.

Hampp, E. G. (1959). Blood sampling and cultural studies in the detection of postoperative bacteraemias. Proc. Inst. Med. Chic., 22, 314.

National Heart Foundation of Australia (1965). Prevention of bacterial endocarditis.

Northrop, P. M., and Crowley, M. C. (1943). Prophylactic use of sulfathiazole in transient bacteremia following extraction of teeth. F. oral Surg., 1, 19.

Okell, C. C., and Elliott, S. D. (1935). Bacteraemia and oral sepsis. Lancet, 2, 869.

Rhoads, P. S., Schram, W. R., and Adair, D. (1950). Bacteremia following tooth extraction: prevention with penicillin and NU 445. F. Amer. dent. Ass., 41, 55.

Shafer, W. G., Hine, M. K., and Levy, B. M. (1963). A Textbook of Oral Pathology, 2nd ed., p. 419. Saunders, Philadelphia and London.

Stirland, R. M., and Shotts, N. (1967). Antibiotic-resistant streptococci in the mouths of children treated with penicillin. Lancet, 1, 405.

Tozer, R. A., Boutflower, S., and Gillespie, W. A. (1966). Antibiotics for prevention of bacterial endocarditis during dental treatment. ibid., 1, 686. 